\title{
The nucleolus: a paradigm for cell proliferation and aging
}

\section{Comai}

\section{Correspondence}

\section{Comai}

Department of Molecular

Microbiology and Immunology

School of Medicine

University of Southern California

2011 Zonal Avenue

Los Angeles, CA 90033-1054

Fax: + 1-323-442-1721

E-mail: comai@ hsc.usc.edu

Presented at the I International Symposium on "Signal Transduction and Gene Expression in Cell Proliferation and Differentiation", São Paulo, SP, Brasil,

August 31-September 2, 1998.

Research supported by the National Institutes of Health, USA, and the American Cancer Society.

Received August 20, 1999 Accepted September 8, 1999
Department of Molecular Microbiology and Immunology, School of Medicine, University of Southern California, and Norris Comprehensive Cancer Center, Los Angeles, CA, USA

\section{Abstract}

The nucleolus is the cellular site of ribosome biosynthesis. At this site, active ribosomal DNA (rDNA) genes are rapidly transcribed by RNA polymerase I (pol I) molecules. Recent advances in our understanding of the pol I transcription system have indicated that regulation of ribosomal RNA (rRNA) synthesis is a critical factor in cell growth. Importantly, the same signaling networks that control cell growth and proliferation and are deregulated in cancer appear to control pol I

Key words

- Nucleolus

- RNA pol I

- Aging

- Transcription

- Werner syndrome transcription. Therefore, the study of the biochemical basis for growth regulation of pol I transcription can provide basic information about the nuclear signaling network. Hopefully, this information may facilitate the search for drugs that can inhibit the growth of tumor cells by blocking pol I activation. In addition to its function in ribosome biogenesis, recent studies have revealed the prominent role of the nucleolus in cell senescence. These findings have stimulated a new wave of research on the functional relationship between the nucleolus and aging. The aim of this review is to provide an overview of some current topics in the area of nucleolus biology, and it has been written for a general readership.

\section{Nucleolus structure}

The nucleolus is a membraneless organelle within the nucleus. The major function of this organelle is ribosome biogenesis, a process that requires transcribing the rDNA, processing the pre-rRNA precursor and assembling the rRNA with the ribosomal proteins $(1,2)$. Each nucleolus contains a cluster of transcriptionally active ribosomal precursor particles at various stages of maturation. The major body of the nucleolus of metabolically active cells is termed the granular component (GC). Embedded in this granular mass are one or more rounded structures called the fibrillar centers (FC). A layer of tightly packed fibrils, the dense fibrillar components (DFC), surrounds the fibrillar center. The genes for the major rRNAs are located in the short arms of the five acrocentric chromosomes. The chromosome regions containing these loci have been named "nucleolus organizing regions" (NOR). In each NOR many copies of the major rRNA gene are tandemly arranged. In total, each genome contains about 300-400 copies of tandemly arranged genes.

\section{rDNA transcriptional machinery}

In the last few years our knowledge of the 
mechanisms that control the expression of the rDNA gene have made great advances $(3,4)$. Mammalian ribosomal DNA transcription by polymerase I (pol I) requires the coordinate assembly on the promoter of at least two factors in addition to RNA pol I, i.e., the upstream binding factor (UBF) and the selectivity factor, SL1 (5). Human UBF is a $97-\mathrm{kDa}$ polypeptide that recognizes the DNA control elements (core and upstream control element; UCE) of the human rRNA promoter in a conformation-specific rather than sequence-specific manner (6-9). Human UBF contains 4 high mobility group (HMG) boxes, highly homologus to nonhistone chromosomal proteins HMG1 and HMG2, which mediate DNA binding. In addition, the $\mathrm{N}$-terminal region has been found to mediate UBF dimerization and a highly acidic carboxy-terminal tail that is necessary for transactivation $(10,11)$. The second essential factor necessary for accurate pol I transcription, SL1, does not bind to the rRNA promoter. However, in the presence of UBF, it forms a strong cooperative DNA-binding complex at the rRNA promoter level that is critical for initiation of transcription $(5,12)$. Mutations in the promoter sequences that affect either the binding of UBF to the DNA template or the interaction of UBF with SL1 result in drastic reduction of transcription activity $(13,14)$. These findings strongly suggest that interactions between UBF and its DNA recognition sequence, and between UBF and SL1, play a major role in pol I transcription. Furthermore, transcription of ribosomal RNA is species-specific (15), and the selectivity factor SL1 is the species-specific factor that directs transcription only from the cognate template (16-19). Interestingly, SL1, similarly to the RNA polymerase II (pol II) factor TFIID, is a protein complex composed of the TATA-binding protein (TBP) and 3 TAFs (TBP-ássociated factors) (20-22). Since a similar TBP/TAF arrangement is also part of RNA polymerase III (pol III) transcription factor TFIIIB, TBP is therefore a universal transcription factor involved in transcription by all three nuclear RNA polymerases. Thus, promoters from all three polymerases have evolved to maintain the same TBP-core subunit. However, each transcriptional machinery uses a different set of TAFs to direct promoter-specific transcription.

\section{Regulation of RNA polymerase I transcription}

\section{Tumor suppressor proteins}

The morphology of the nucleolus is highly variable and depends on the overall cellular activity. It is well known among pathologists that the hypertrophy of the nucleolus is one of the most consistent cytological features of cancer cells. Therefore, it is often included among the diagnostic markers of malignancy (23). Nucleoli in malignant cells are usually large and frequently quite compact. This is likely because fast proliferating cells have a higher demand for ribosomes than slowly proliferating cells. Since the rapid growth of tumors requires elevated rates of biosynthesis, transcription by pol I may need to increase during tumor development. Accordingly, it is conceivable that the same cellular networks that are deregulated in cancer cells are likely to control pol I activity. To determine the relationship between control of cell growth and ribosomal RNA synthesis, recent studies have investigated the role of tumor suppressor proteins in rRNA transcription. The retinoblastoma tumor suppressor protein $\mathrm{pRb}$ suppresses both the growth and proliferation of cells and several studies have demonstrated its key role in the regulation of many cell cycle regulatory genes transcribed by pol II (24). Work by Cavanaugh et al. (25) led to the finding that $\mathrm{pRb}$ can suppress the synthesis of rRNA by pol I, providing the first evidence that a global repression of genes would be necessary to arrest cell growth and proliferation. The in- 
volvement of $\mathrm{pRb}$ in regulation of pol I transcription was confirmed using immunofluorescence microscopy to visualize $\mathrm{pRb}$ in the nucleolus of differentiated human monocytic-like cells (25). Differentiation of these cells is associated with a dramatic down regulation of rRNA synthesis and a rapid accumulation of $\mathrm{pRb}$ within the nucleolus. In vitro transcription and protein-protein interaction assays indicated that $\mathrm{pRb}$ binds to UBF and specifically inhibits the activity of this transcription factor $(25,26)$. Inhibition appears to require a region of $\mathrm{pRb}$ named the $\mathrm{Rb}$ pocket, which has been shown to be involved in interactions with a number of cellular factors and viral proteins $(24,27)$. Thus, it appears that $\mathrm{pRb}$ influences the transcriptional activity of pol I by direct interaction with the transcription factor UBF. Although these results indicated that an interaction between $\mathrm{pRb}$ and UBF is required for the inhibition of RNA pol I activity, many interesting questions were left unanswered. For example, we do not know which region of UBF is involved in this interaction. Also, little is known about the mechanism of UBF repression: does $\mathrm{pRb}$ prevent $\mathrm{UBF}$ from binding to DNA or does it block the interactions between UBF and SL1/RNA pol I? In this regard, conflicting data have been presented $(25,26)$, and therefore a more detailed analysis should provide more conclusive evidence for the actual mechanism of repression. In summary, because of the documented effects of pRB on transcription by RNA polymerase II and III (28), pRb provides an important regulatory link between the three RNA polymerase systems that, when deregulated or inactivated, can lead to uncontrolled cell growth and proliferation.

\section{Viral oncogenes}

Oncogenic DNA tumor viruses have been known to stimulate cell proliferation and induce cell transformation. Neoplastic transformation by small oncogenic DNA viruses such as simian virus 40 (SV40) and polyoma virus is directly related to specific proteins called $\mathrm{T}$ antigens, encoded by the viral genome (29). SV40 large T antigen is a sequence-specific DNA-binding protein, which has been shown to play a key role in viral gene expression (29). Large T antigen is also essential for initiating viral replication. A second antigen, the small $t$ antigen, has little effect on viral gene expression, and it appears to be involved in cell transformation. In permissive cells, SV40 large T antigen plays many roles in ensuring the survival and proliferation of the virus. In nonpermissive cells, large $\mathrm{T}$ antigen integrates into the genome and its constitutive expression induces oncogenic transformation and cell proliferation. In both instances, large $\mathrm{T}$ antigen partially modulates the cellular environment by binding and inactivating the cellular proteins $\mathrm{pRb}$ and $\mathrm{p} 53$, both of which suppress cell growth $(27,29)$. In addition, large $T$ antigen enhances the expression of several cellular genes involved in cell cycle progression and cell growth. All these cellular alterations are part of the general strategy adopted by SV40 large $T$ antigen to maintain a healthy cellular environment which insures either the survival and proliferation of the virus in permissive cells, or the proliferative state of cells transformed with large $\mathrm{T}$ antigen. Ribosomal RNA synthesis plays a key role in the maintenance of a viable cell, and is tightly linked to the growth state of the cell. Therefore, it is not surprising that the rDNA genes are among the cellular targets of regulation by large $\mathrm{T}$ antigen. Our laboratory has recently dissected the mechanism of this stimulatory process, and we have determined that large $\mathrm{T}$ antigen is brought to the ribosomal RNA promoter through protein-protein interactions with the TBP-TAF complex SL1 (30). Similar studies have shown that large T antigen stimulation of genes transcribed by pol II and pol III is also achieved by association of large $\mathrm{T}$ antigen with the corresponding TBP-TAF complex, namely TFIID and 
TFIIIB (31-33). Thus, large T antigen appears to have adopted a similar mechanism to target genes transcribed by the three classes of RNA polymerase. Remarkably, our recent studies have revealed that large $T$ antigen is strongly associated with a kinase activity that phosphorylates the transcription factor UBF (34). UBF phosphorylation stabilizes the protein-protein interactions between UBF and SL1 (35), and is necessary for stimulation of transcription (34-39). These findings led us to propose that UBF is the actual functional target of large $\mathrm{T}$ antigen activation, and SL1 serves as a docking site for the recruitment of the viral protein and its associated kinase activity to the promoter region. We do not know if this kinase activity is also involved in activation of pol II and pol III genes. However, the similarities in the way that large $\mathrm{T}$ antigen is recruited to different promoters suggest that a common mechanism may underlie the activation of diverse genes by this viral protein. Given the rapid progress in this field, it is likely that this issue will be resolved in the near future.

\section{The nucleolus and aging}

Recent studies point to an important role for the nucleolus in the senescence of eukaryotic cells. Studies on the yeast Saccharomyces cerevisiae have revealed that the rDNA is the $A G E$ locus and that some nucleolar functions may be negatively affected in old yeast cells $(40,41)$. Recent studies with cells bearing a mutated silent information regulator (Sir 4) protein indicated that there is a dramatic relocalization of Sir proteins from the telomeres to the nucleolus, which extends the yeast life span. The Sir 4 gene is required for transcriptional repression of silent mating-type high mobility $(H M)$ genes, and genes located adjacent to the telomeres. More importantly, the relocalization of Sir proteins is also seen in old wild-type cells. These findings provide strong evidence that the nucleolus is a physiologically important site for Sir protein action and has a crucial role in cell senescence. Further convincing data on the role of the nucleolus in the aging process are derived from studies of another yeast gene, $S g s 1$. Sgsl encodes a protein with DNA helicase activity that is closely related to the human Werner gene (WRN) (42). Homozygous mutations of the $W R N$ gene cause the human premature aging disease known as Werner syndrome (43). Studies in yeast indicated that the Sgs1 protein is localized to the nucleolus and Sgsl mutants display a premature aging phenotype (44). Associated with the premature aging process, there is a dramatic enlargement and often fragmentation of the nucleolus (45). In addition, in these cells there is a redistribution of Sir proteins to the nucleolus, as observed in aging wild-type cells. These observations strongly suggest that, at least in yeast cells, some form of nucleolar damage, which occurs prematurely in $\mathrm{Sgs} 1$ mutant cells, is a direct cause of premature senescence. The age-related functions of Sir and Sgs1 proteins remain to be determined, although they appear to involve some fundamental aspects of nucleolus function which may affect expression of the rDNA genes and, ultimately, protein synthesis. The homology between Sgsl and the Werner syndrome gene led to the question of whether the WRN protein was also involved in some aspects of nucleolus biology. Quite intriguingly, the WRN protein is also localized in the nucleolus of human cells $(46,47)$. However, old cell nucleolar fragmentation is not usually seen in cells of human origin. Therefore, it is unlikely that nucleolar fragmentation causes aging of human cells. On the other hand, recent studies indicate a close relationship between nucleolar localization of the WRN protein and pol I transcriptional activity, suggestive of a role of the WRN protein in some aspects of rDNA transcription (47). In conclusion, although there are a few differences in aging between yeast and humans, these findings strongly suggest a conserved 
mechanism of cellular aging that involves nucleolar structure and function. Hopefully, future studies will yield new insights into the role of the nucleolus in the mechanisms of aging-related processes.

\section{References}

1. Melese T \& Xue Z (1995). The nucleolus: an organelle formed by the act of building a ribosome. Current Opinion in Cell Biology, 7: 319-324.

2. Hadjiolov AA (1985). The nucleolus and ribosome biogenesis. Cell Biology Monographs, 12: 1-267.

3. Moss T \& Stefanovaski VY (1995). Promotion and regulation of ribosomal transcription in eukaryotes by RNA polymerase I. Progress in Nucleic Acid Research and Molecular Biology, 50: 25-66.

4. Paule MR (1998). Transcription of Ribosomal RNA Genes by Eukaryotic RNA Polymerase I. Springer-Verlag, New York.

5. Bell SP, Learned RM, J antzen HM \& Tjian R (1988). Functional cooperativity between transcription factors UBF1 and SL1 mediates human ribosomal RNA synthesis. Science, 241: 1192-1197.

6. J antzen HM, Admon A, Bell SP \& Tjian R (1990). Nucleolar transcription factor hUBF contains a DNA-binding motif with homology to HMG proteins. Nature, 344: 830-836.

7. Hisatake $K$, Nishimura $T$, Maeda $Y$, Hanada $K$, Song $C Z \&$ \& Muramatsu $M$ (1991). Cloning and structural analysis of CDNA and the gene for mouse transcription factor UBF. Nucleic Acids Research, 19: 4631-4637.

8. Copenhaven GP, Putnam CD, Denton ML \& Pikaard CS (1994). The RNA polymerase I transcription factor UBF is a sequencetolerant HM G-box protein that can recognize structural nucleic acids. Nucleic Acids Research, 22: 2651-2657.

9. Bazett-J ones DP, Leblanc M, Herfort M \& Moss T (1994). Short-range DNA looping by the Xenopus HMG-box transcription factor, xUBF. Science, 264: 1134-1137.

10. McStay B, Hu CH, Pikaard CS \& Reeder RH (1991). xUBF and Rib 1 are both required for formation of a stable polymerase I promoter complex in X. laevis. EMBO J ournal, 10: 2297-2303.

11. J antzen HM, Chow AM, King DS \& Tjian R (1992). Multiple domains of the RNA polymerase I activator hUBF interact with the TATA-binding protein complex hSL1 to mediate transcription. Genes and Development, 6: 1950-1963.

12. Learned RM, Leamed TK, Haltiner MM \&
Tjian R (1986). Human rRNA transcription is modulated by the coordinate binding of two factors to an upstream control element. Cell, 45: 847-857.

13. Haltiner MM, Smale ST \& Tjian R (1986). Two distinct promoter elements in the human rRNA gene identified by linker scanning mutagenesis. Molecular and Cellular Biology, 6: 227-235.

14. Nagamine $M$, Kishimoto $T$, Aono J , Kato H, Kominmi R \& Mutamatsu M (1987). Sequestration analysis for the RNA polymerase I transcription factors with various deletion and point mutations reveals different functional regions of the mouse rRNA gene promoter. Molecular and Cellular Biology, 7: 1486-1495.

15. Grummt I, Roth E \& Paule M (1982). Ribosomal RNA transcription in vitro is species specific. Science, 296: 173-174.

16. Bell SP, Pikaard CS, Reeder RH \& Tjian R (1989). Molecular mechanisms governing species-specific transcription of ribosomal RNA. Cell, 59: 489-497.

17. Bell SP, J antzen HM \& Tjian R (1990). Assembly of alternative multiprotein complexes directs rRNA promoter selectivity. Genes and Development, 4: 943-954.

18. Leamed RM, Cordes S \& Tjian R (1985). Purification and characterization of a transcription factor that confers promoter specificity to human RNA polymerase I. Molecular and Cellular Biology, 5: 13581369.

19. Mishima $Y$, Financsek $R$, Kominami $R \&$ Muramatsu M (1982). Fractionation and reconstitution of factors required for accurate transcription of mammalian rRNA genes: identification of a species-dependent factor. Nucleic Acids Research, 10: 6659-6670.

20. Comai L, Tanese N \& Tjian R (1992). The TATA-binding protein and associated factors are integral components of the RNA polymerase I transcription factor, SL1. Cell, 68: 965-976.

21. Comai L, Zomerdijk J C, Beckmann H, Zhou S, Admon A \& Tjian R (1994). Reconstitution of transcription factor SL1: exclusive binding of TBP by SL1 or TFIID subunits. Science, 266: 1966-1972.

22. Eberhard D, Tora L, Egly J M \& Grummt I (1993). A TBP-containing multiprotein complex (TIF-IB) mediates transcription specificity of murine RNA polymerase I. Nucleic Acids Research, 21: 4180-4186.

23. Derenzini $M$, Trere $D$, Pession $A$, Montanaro L, Sirri V \& Ochs RL (1998). Nucleolar function and size in cancer cells. American J ournal of Pathology, 152: 1291-1297.

24. Weinberg RA (1995). The retinoblastoma protein and cell cycle control. Cell, 81 : 323-330.

25. Cavanaugh AH, Hempel WM, Taylor LJ Rogalsky V, Todorov G \& Rothblum LI (1995). Activity of RNA polymerase I transcription factor UBF blocked by $\mathrm{Rb}$ gene product (see comments). Nature, 374: 177-180.

26. Voit R, Schafer K \& Grummt I (1997). Mechanism of repression of RNA polymerase I transcription by the retinoblastoma protein. Molecular and Cellular Biology, 17: 4230-4237.

27. Nevins J R (1994). Cell cycle targets of the DNA tumor viruses. Current Opinion in Genetics and Development, 4: 130-134.

28. White RJ (1997). Regulation of RNA polymerase I and III by the retinoblastoma protein: a mechanism for growth control? Trends in Biochemical Sciences, 22: 77 80.

29. Fanning E \& Knippers R (1992). Structure and function of simian virus 40 large tumor antigen. Annual Review of Biochemistry, 61: 55-85.

30. Zhai W, Tuan J A \& Comai L (1997). SV40 large $T$ antigen binds to the TBP-TAF(I) complex SL1 and coactivates ribosomal RNA transcription. Genes and Development, 11: 1605-1617.

31. Damania B \& Alwine J C (1996). TAF-like function of SV40 large T antigen. Genes and Development, 10: 1369-1381.

32. Damania B, Mital R \& Alwine J C (1998). Simian virus 40 large $T$ antigen interacts with human TFIIB-related factor and small nuclear RNA-activating protein complex for transcriptional activation of TATA-containing polymerase III promoters. Molecular and Cellular Biology, 18: 1331-1338.

33. J ohnston SD, Yu X-M \& Mertz JE (1996). The major transcriptional transactivator domain of simian virus 40 large $T$ antigen associates nonconcurrently with multiple 
components of the transcriptional preinitiation complex. J oumal of Virology, 70: 1191-1202.

34. Zhai W \& Comai L (1999). A kinase activity, associated with simian virus 40 large $\mathrm{T}$ antigen, phosphorylates UBF and promotes the formation of a stable initiation complex between UBF and SL1. Molecular and Cellular Biology, 19: 2791-2802.

35. Tuan J, Zhai W \& Comai L (1999). The recruitment of the TATA-binding protein -

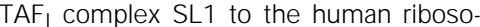
mal DNA promoter is mediated by the carboxy-terminal activation domain of UBF and is regulated by UBF phosphorylation. Molecular and Cellular Biology, 19: 2872-2879.

36. Voit R, Kuhn A, Sander EE \& Grummt I. (1995). Activation of mammalian ribosomal gene transcription requires phosphorylation of the nucleolar transcription factor UBF. Nucleic Acids Research, 23: 2593-2599.

37. Voit R, Schnapp A, Kuhn A, Rosenbauer $H$, Hirschamann $P$, Stunnenberg HG \& Grummt I (1992). The nucleolar transcription factor mUBF is phosphorylated by casein kinase II in the C-terminal hyperacidic tail which is essential for transactiva- tion. EMBO J ournal, 11: 2211-2218.

38. O'Mahony DJ , Xie WQ, Smith SD, Singer HA \& Rothblum LI (1992). Differential phosphorylation and localization of the transcription factor UBF in vivo in response to serum deprivation. In vitro dephosphorylation of UBF reduces its transactivation properties. J oumal of Biological Chemistry, 267: 35-38.

39. O'Mahony DJ, Smith SD, Xie $W$ \& Rothblum LI (1992). Analysis of the phosphorylation, DNA-binding and dimerization properties of the RNA polymerase I transcription factors UBF1 and UBF2. Nucleic Acids Research, 20: 1301-1308.

40. Kennedy BK, Gotta M, Sinclair DA, Mills K, McNabb DS, Murthy M, Pak SM, Laroche T, Gasser SM \& Guarente L (1997). Redistribution of silencing proteins from telomeres to the nucleolus is associated with extension of life span in S. cerevisiae. Cell, 89: 381-391.

41. Gotta M, Strahl-Bolsinger S, Renauld H, Laroche T, Kennedy BK, Grunstein M \& Gasser SM (1997). Localization of Sir2p: the nucleolus as a compartment for silent information regulators. EMBO J ournal, 16: 3243-3255.

42. Watt PM, Hickson ID, Borts RH \& Louis
EJ (1996). SGS1, a homologue of the Bloom's and Wemer's syndrome genes, is required for maintenance of genome stability in Saccharomyces cerevisiae. Genetics, 144: 935-945.

43. Thweatt R \& Goldstein S (1993). Werner syndrome and biological ageing: a molecular genetic hypothesis. Bioessays, 15 421-426.

44. Sinclair DA, Mills K \& Guarente L (1997). Accelerated aging and nucleolar fragmentation in yeast sgs1 mutants (see comments). Science, 277: 1313-1316.

45. Sinclair DA \& Guarente L (1997). Extrachromosomal rDNA circles - a cause of aging in yeast. Cell, 91: 1033-1042.

46. Marciniak RA, Lombard DB, J ohnson FB \& Guarente L (1998). Nucleolar localization of the Werner syndrome protein in human cells. Proceedings of the National Academy of Sciences, USA, 95: 68876892

47. Gray MD, Wang L, Youssoufian H, Martin GM \& Oshima J (1998). Wemer helicase is localized to transcriptionally active nucleoli of cycling cells. Experimental Cell Research, 242: 487-494. 